\title{
An Article Submitted to
}

\section{The B.E. Journal of Theoretical Economics}

Manuscript 1356

\section{Interbank Competition with Costly Screening}

\author{
Xavier Freixas* \\ Sjaak Hurkens ${ }^{\dagger}$ \\ Alan D. Morrison \\ Nir Vulkan**
}

*xavier.freixas@upf.edu

†sjaak.hurkens@gmail.com

‡Oxford Saïd Business School, alan.morrison@sbs.ox.ac.uk

**nir.vulkan@said-business-school.oxford.ac.uk

Copyright (c) 2007 The Berkeley Electronic Press. All rights reserved. 


\title{
Interbank Competition with Costly Screening*
}

\author{
Xavier Freixas, Sjaak Hurkens, Alan D. Morrison, and Nir Vulkan
}

\begin{abstract}
We analyze credit market equilibrium when banks screen loan applicants. When banks have a convex cost function of screening, a pure strategy equilibrium exists where banks optimally set interest rates at the same level as their competitors. This result complements Broecker's (1990) analysis, where he demonstrates that no pure strategy equilibrium exists when banks have zero screening costs. In our set up we show that interest rate on loans are largely independent of marginal costs, a feature consistent with the extant empirical evidence. In equilibrium, banks make positive profits in our model in spite of the threat of entry by inactive banks. Moreover, an increase in the number of active banks increases credit risk and so does not improve credit market efficiency: this point has important regulatory implications. Finally, we extend our analysis to the case where banks have differing screening abilities.
\end{abstract}

KEYWORDS: Credit market, screening, banking, entry

${ }^{*}$ We would like to thank Ramon Caminal and seminar audiences at SED2004 (Mallorca) and the Second World Congress of Game Theory 2004 (Marseille) for their comments. We thank Victor Pavon-Villamayor for his help in collecting the empirical evidence. Financial support from CONSOLIDER-INGENIO 2010 (CSD2006-00016) and SEJ2006-01717 (MEC) is gratefully acknowledged. 


\section{Interbank Competition with Costly Screening}

\section{Introduction}

This paper explores the nature of equilibrium in the credit market under asymmetric information when banks are able to screen their customers. Information asymmetries are central to credit markets. There is nowadays a basic agreement among academics that banks exist because they monitor firms (Diamond, 1984; Gale and Hellwig, 1985; Holmström and Tirole, 1993). Hence, models of the credit market should incorporate a screening-monitoring role for banks. It is widely appreciated that introducing asymmetric information into models of the credit market yields equilibria with specific features. Contributions like those of Stiglitz and Weiss (1981), Sharpe (1990) and Rajan (1992) exhibit equilibrium phenomena such as credit rationing and ex post monopoly of information, which are absent from standard delivery-versus-payment markets.

Still, credit market models seem seldom to acknowledge the importance of screening. This creates an apparent schism between models of bank/firm contracts, where screening is central, and models of the credit market, where screening is typically non-existent. Fortunately, Broecker's (1990) model provides a bridge between the two by exploring credit market equilibrium when banks screen firms. However, in Broecker's equilibrium banks use mixed strategies to assign interest rates for loans. This is an unattractive feature for various reasons. First, it yields no empirical implications; second, it makes it difficult to study the comparative statics or the welfare properties of the model; third, ex-post banks will have incentives to change their realized interest rates so that a mixed strategy equilibrium does not represent a stable situation. Hence, although Broecker's elegant contribution is a step in the right direction, we think that it is worth devoting some effort to extending it.

The intuition behind Broecker's contribution is straightforward. When banks screen loan applicants, the order in which firms approach banks is important. Rational firms will apply firstly to the banks which post the lowest interest rates. As a result, a bank may ensure by lowering its interest rate that it has first choice from the population of loan applicants. So the bank simultaneously alters the price at which it lends, and the marginal cost of lending. Hence a bank may be able to profit by undercutting its competitors. Setting price equal to marginal cost in the traditional way may therefore not yield an equilibrium. This is at odds with standard microeconomic theory and hence opens new avenues for exploration. This is precisely the object Published by The Berkeley Electronic Press, 2007 of our paper.

Our work is primarily motivated by the divide between the theoretical justification for banks 
and current models of the credit market Submission to The B. Exanning the divide we wish to address two specific points.

Firstly, mixed strategy equilibria are rather unsatisfying in the context of price competition. Once interest rates realize, banks would always want to change them immediately. For example, the bank with the lowest interest rate would always prefer to increase it. Moreover, the empirical evidence does not support the conclusion that bank loan rates move erratically and, across banks, independently all of the time. Finally, it is hard to derive empirical predictions from mixed strategy equilibria.

Secondly, we wish to understand whether the credit market should be thought of as a "natural monopoly". If so, credit market equilibria should be characterized by equilibrium profits. This question is related to the relationship between competition and financial stability, which has been investigated in models where banks have the choice of their riskiness levels (as for example in Matutes and Vives, 2000), but never in a set-up where the level of screening and of credit risk in the banking industry is endogenous because it depends on the number of banks an applicant is able to visit.

Clearly, the answers to these points will inform regulatory attitudes towards credit market entry, and hence will have important policy implications. We address these issues in a model of a credit market in which banks face an adverse selection problem due to heterogeneity in firm repayment probabilities. We assume that banks have to rely upon active monitoring when responding to a firm's application for a loan. The monitoring technology is imperfect and independent across banks. Banks must account for the fact that their loan applicants may have already been rejected by other banks. In particular, a single bank offering the lowest interest rates will on average attract better applicants than banks charging higher interest rates.

We extend Broecker's framework by assuming that banks incur a screening cost which is increasing and convex in the number of applicants which they screen. A simple example would be a capacity constraint which renders it very costly (or just simply impossible) to screen all applicants. Our main result is that pure strategy equilibria exist for sufficiently convex screening costs. With convex screening costs, undercutting one's competitors in order to gain market share and an improved applicant pool may be discouraged by the consequential increase in screening costs. The equilibrium is characterized by indeterminacy, as banks can coordinate on a number of different interest rates. This is an interesting feature of our model, as it implies

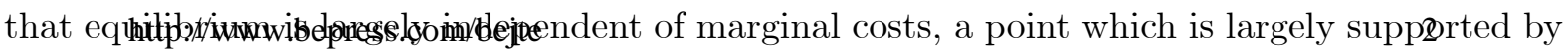
empirical research as we show in the next section. 
It is also worth emphasizing the existence in our model of positive profits for banks in equilibrium. This contrasts with Broecker's result that, with sufficiently many banks, the mixed strategy equilibrium yields zero profits for all banks. Our model has a number of free entry equilibria, characterized by differing numbers of active banks. The more banks that decide to be active in equilibrium, the lower the average quality of borrowers and the higher the equilibrium interest rate charged by all of them. A bad project therefore has a higher chance of securing a loan when there are more banks. Hence it seems reasonable to expect that welfare will be decreasing in the number of active banks. We demonstrate for a specific screening cost function that this is indeed the case, and we provide a detailed numberical example with a different cost function in which increasing the number of banks lowers welfare. Hence, our paper provides additional support for the common statement that regulators should restrict entry to the banking sector.

Finally, we introduce some element of natural oligopoly to our model by examining the case where banks differ in their screening ability. We show that an inferior bank suffers losses whenever a superior bank charges the same or a lower interest rate. When interest rates are the same, the reason is that high quality borrowers will in the first instance approach the lender with the superior screening technology while low quality borrowers will approach the other bank. Hence the bank with a comparatively weaker screening technology will also face an inferior pool of borrowers. When interest rates differ the bank with the weaker screening technology will face a weaker pool of borrowers because all have already been rejected by the bank with the stronger technology. We characterize the equilibria in section 7 .

Our work is related to a number of papers. Firstly, as discussed at length above, Broecker (1990) models price competition amongst banks with a zero screening cost, and shows that the only equilibria are in mixed strategies. His results have been widely discussed in the lending literature (von Thadden, 2004) and extended by Dell'Ariccia, Friedman and Marquez (1999) to analyze entry in the banking industry and by Marquez (2002) to explore the effect of increased competition on the quality of credit. Pure strategy equilibria obtain in our model for a sufficiently convex screening cost function. This result is slightly related to Riordan (1993), who proves the existence of pure strategy equilibrium when banks receive signals from a continuous distribution and interest rates are charged conditional on the signal (which allows price discrimination).

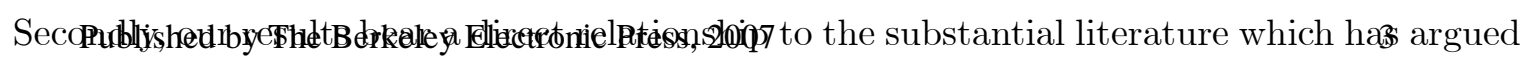
that welfare is enhanced by allowing banks to obtain non-competitive rents, since this provides 
them with the right incentives. This could be a result of horizontal differentiation (Chiappori et al., 1995, and Matutes and Vives, 2000), because banks then choose to reduce the risk of the assets (Suarez, 1998, Matutes and Vives, 2000), or because they extract ex post rents from their lending relationships (Sharpe, 1990, Rajan, 1992, von Thadden, 1994). The possibility that competition may be inefficient is also acknowledged by Petersen and Rajan (1995), as in their model a more competitive banking market is not necessarily a more efficient one because competition makes it harder for young firms to build banking relationships and hence to obtain a loan.

Finally, our paper is related to Dastidar (1995), who shows that in a setting of oligopolistic price competition with homogeneous goods and convex costs, pure strategy equilibria exist when firms are obliged to serve all demand. As in our model, firms do not have incentives to undercut to increase market share since this would increase their average production cost and lower overall profits. In our model, banks can increase market share and improve the average quality of applicants by undercutting competing banks, but again, the convexity of (screening) costs renders such strategies unsuccessful.

We present our analysis as follows. The next section provides stylized facts and empirical evidence which are consistent with our model. Section 3 describes a model of a credit market in which loan applications and loan screening are costly. Section 4 demonstrates the existence in our model of pure strategy equilibria for an exogenously given number of banks; comparative statics are derived in section 5, and section 6 provides a numerical example of the equilibrium. In section 7 we analyze an extension with heterogeneous bank monitoring skills. Section 8 concludes.

\section{Stylized Facts and Empirical Evidence}

In this section we present evidence from the existing literature which is supportive of our work.

\subsection{Screening Costs}

Banks use filters to screen consumers according to their credit worthiness: this provides evidence of costly screening. An important example of costly screening is the use for a fee of common databases in assessing applications for credit. Credit analysis of consumer loans (including credit

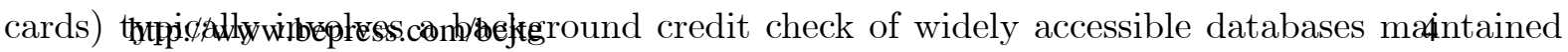
by one of the three large consumer credit bureaus (in the US they are Equifax, Experian/TRW 
and Trans Union). Standardized_credit scoring models are now commercially available for credit cards, mortgage lending, and small business. To the extent that the updating and collecting of new information is costly, the use of these databases for screening purposes is not free (as a reference point, Equifax charges between 50-100 US dollars per single inquiry).

\subsection{Sticky Interest Rates}

Ausubel (1991) finds evidence that credit card interest rates have been exceptionally sticky relative to the cost of funds. Ausubel studies the US market for credit cards, and finds that banks' cost of funds (the marginal cost of producing loans) has fallen rapidly from its level in the late 1970s. Although this fall has been accompanied by a drop in rates on collateralized loans, credit card rates have remained relatively high. In particular, Ausubel presents evidence that credit card rates have been particularly sticky in the 1980s. In a regression of credit card rates on the cost of funds over the 1982-1987 period, he finds that the cost of funds was statistically significant, but the magnitude of the coefficient (about 0.05, depending on the specification) suggested that the cost of funds was economically insignificant in explaining credit card rates. It is important to observe that a competitive market model would predict a coefficient near to one. The evidence then shows that it takes many years for the price to adjust to changes in marginal cost when the rate of adjustment is only on the order of $5 \%$ per quarter.

This stickiness is surprising since the cost of funds is the primary determinant of the marginal cost of lending via credit cards, and it is usually the only component of marginal costs that varies widely from quarter to quarter. A model of continuous spot market equilibrium would predict a substantial degree of connection between the interest rate charged on credit cards and the bank's cost of funds. However, the evidence available shows that credit card interest rates were highly sticky during the decade of the 1980s.

Using roughly the same data employed by Ausubel in his study, we constructed the following graph which shows that the relative stickiness of credit card interest rates with respect to the cost of funds for the period 1980-2003.

Ausubel also reports that the credit card industry defended its high interest rates in the midto-late 1980s, in part, by asserting that the increased spread between the credit card interest rate and the cost of funds had been caused by an increase in the industry's rate of bad loans.

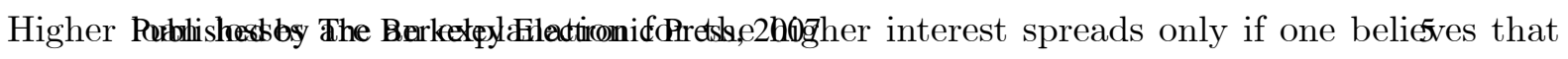
the latter are solely determined by costs. If credit card interest rates are determined otherwise, 


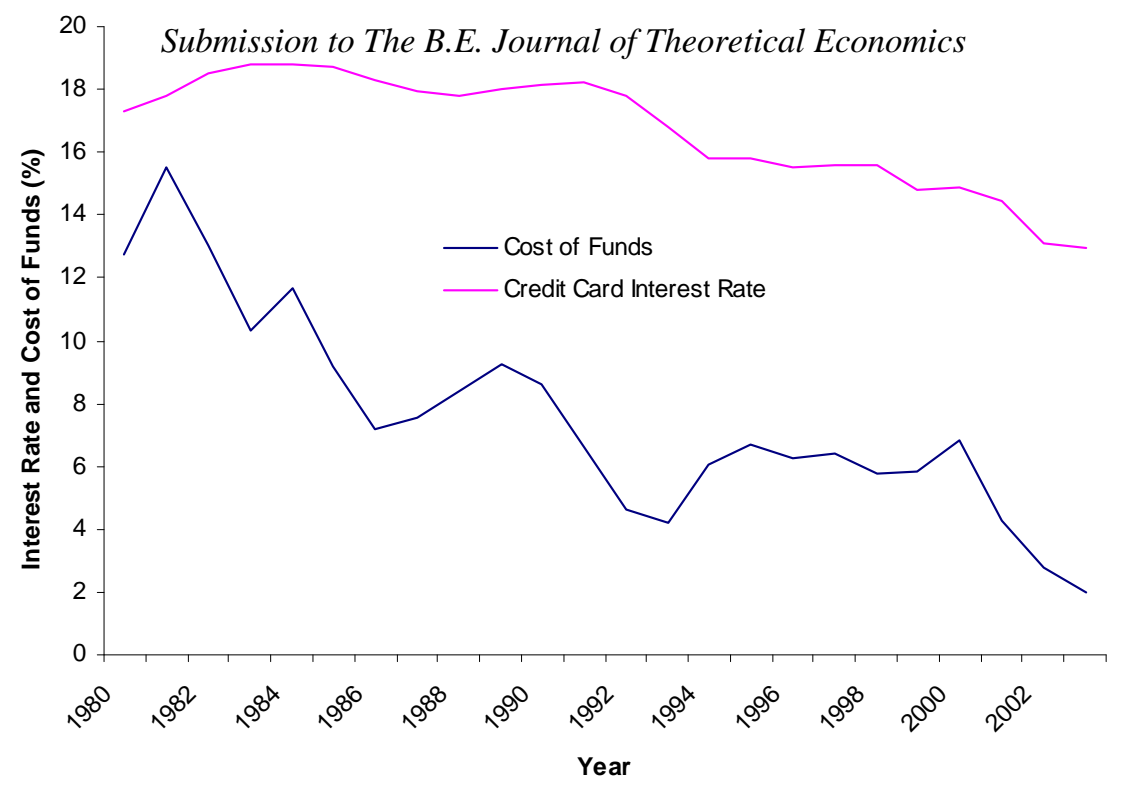

Figure 1: Source: Credit Card Interest Rates from "The Profitability of Credit Card Operations of Depositary Institutions", Board of Governors of the Federal Reserve System, Annual Report, June 2004. Cost of Funds is the one-year US Treasury bill yield plus 0.75 percent as defined by Ausubel (1991).

then the causation may run in the reverse direction: an increased interest spread may cause an increase in charge-offs.

Calem and Mester (1995), drawing data from the Federal Reserve's 1989 Survey of Consumer Finances, also provide empirical evidence in support of the low responsiveness of credit card interest rates to changes in bank's costs of funds. In particular, these authors support the argument that this degree of stickiness can be explained by: (a) cardholders' search and switching costs, and (b) the fact that banks would face an adverse selection problem if they were to reduce their interest rate unilaterally. On the other hand, Hannan and Berger (1991) studied banks' decisions to change local deposit rates in response to exogenous changes in interest rates. Using monthly observations of deposit rates offered by 398 banks located in 132 US local banking markets covering the period from September 1983 to December 1986, they found that price rigidity is significantly greater in markets characterized by higher levels of concentration and that deposit rates are significantly more rigid when the stimulus for a change is upward rather than downward.

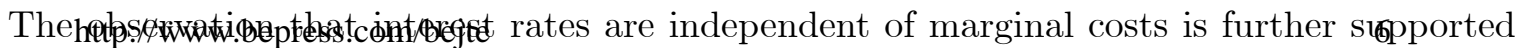
in Hannan and Berger (1991) and Mester (1994). 
Clearly, there are other explanations for the stickiness of interest rates. The model presented in this paper can be seen as an additional explanation of this important economic phenomenon, but is not intended to explain it entirely.

\subsection{Interest Rates and Market Structure}

Shaffer (1998) reports that virtually all structural models or other "new empirical industrial organisation" studies of banking find essentially competitive loan pricing not only nationwide, but also in highly concentrated markets such as Canada (where the industry is dominated by fewer than half a dozen large banks), rural counties in a unit banking state, or even a banking duopoly. This is an important finding since if conduct is competitive and if costs do not vary systematically with market structure, then the interest rate on loans will not be a function of the number of banks. Interestingly, Shaffer notes that anecdotal evidence from bankers suggests that they do respond to the practices, but not consciously to the number, of rival lenders.

On the other hand, Shaffer, using a cross-sectional sample of nearly 3,000 banks in over 300 single geographic markets across the US as of year-end 1990, found that loan chargeoff rates are a significantly increasing function of the total number of banks in the geographic market. The estimated magnitude of the effect implies that each additional rival bank drives up the gross chargeoff rate of each incumbent by 0.10 basis points.

In our model, proposition 1 shows that increased bank competition may be inefficient: namely, that more projects will be funded in equilibrium when there are more banks. As a result, credit risk will increase and so too will interest rates. Empirical support for these findings is provided by Shaffer (1998), who finds that "Among mature banks, those operating in less concentrated banking markets experience significantly higher chargeoff rates for commercial loans and for total loans" (p.389). Thus, the policy implication of our results is that it might be efficient to restrict entry into the credit market, as this reduces the number of chances for poor borrower to obtain funds.

Emons' (2001) work on house insurance is also related to our paper. He presents a model in which house owners can apply for insurance from multiple providers without investing in safety measures. As a result, both prices and the number of damage claims are higher in competitive markets than in a monopolistic setting. In Switzerland and Germany some regions have a monopolistic insurance market, while others are competitive. Emons provides evidence from Published by The Berkeley Electronic Press, 2007 these markets which is consistent with our theory. 


\section{Submission to The B.E. The Model Tof Theoretical Economics}

Our model is a modified version of Broecker (1990). We consider a credit market with a continuum $[0,1]$ of risk-neutral firms, each of which wishes to borrow $\$ 1$ to invest in a project which will return $\$ X$ if it succeeds and $\$ 0$ if it fails. The success probability of type $a$ firms is $p_{a}$ and of type $b$ firms is $p_{b}$, where $0 \leq p_{a}<p_{b} \leq 1$. A firm's type is its private information. The proportion $l \in(0,1)$ of type $a$ firms is common knowledge.

There are $N \geq 2$ risk neutral banks in the market which can raise any amount of funds at a unit interest rate. If a bank lends at a gross interest rate $r$ to $\alpha$ type $a$ firms and to $\beta$ type $b$ firms then its profit will be $\alpha\left(p_{a} \min (X, r)-1\right)+\beta\left(p_{b} \min (X, r)-1\right)$. Banks have access to an imperfect monitoring technology. The technology assigns each loan applicant to a category $C \in\{A, B\}$. We define

$$
q(C \mid c)=P\{\text { Applicant is assigned to } C \in\{A, B\} \mid \text { Applicant's type is } c \in\{a, b\}\} .
$$

We write $q_{c}$ for $q(A \mid c)$ so that:

$$
\begin{aligned}
& q(A \mid a)=q_{a}, \quad q(B \mid a)=1-q_{a} \\
& q(A \mid b)=q_{b}, \quad q(B \mid b)=1-q_{b} .
\end{aligned}
$$

We do not require, and we do not make, the simplifying assumption $q_{a}=1-q_{b}$ characteristic of a completely symmetric test.

We adopt Broecker's assumption that screening is informative but imperfect:

$$
0<q_{b}<q_{a}<1
$$

It is an easy matter to show as Broecker does that this implies that

$$
\bar{p}_{A}<\bar{p}<\bar{p}_{B},
$$

where $\bar{p}_{A}$ and $\bar{p}_{B}$ are respectively the average success probability of category $A$ and $B$ firms, when there is only one bank where firms can apply, and $\bar{p}=l p_{a}+(1-l) p_{b}$ is the average success probability of all firms. The fact that screening is imperfect causes an adverse selection effect when there are at least two banks. For example, assume two banks charge the same interest rate and, in first instance, each bank attracts half of the firms. The average success probability of those firms is of course $\bar{p}$. However, firms that are rejected by their first bank will apply to the other bank. The average success probability of firms who have failed one test is strictly http://www.bepress.com/bejte

lower than $\bar{p}$, since tests are informative. The overall success probability of applicants at any of the banks is therefore also strictly below $\bar{p}$. 
We adopt the following additional assumption from Broecker's paper, which implies that at least one bank will not make losses if it charges $r=X$ to category $B$ firms:

$$
\bar{p}_{B} X-1>0 .
$$

Broecker also assumes that $\bar{p}_{A} X-1<0$, so that banks do not wish to lend to category $A$ firms. We will make the slightly stronger assumption that banks do not want to lend to firms that are not screened at all. Our assumption thus emphasizes the role of banks in credit markets: ${ }^{1}$

$$
\bar{p} X-1<0 .
$$

Broecker assumes that applying for a loan is costless, and that banks incur no screening costs. We depart from his model by incorporating application and screening costs:

There is a cost $\varepsilon>0$ of applying for a loan;

The cost of screening $x$ applicants is $C(x)$,

$$
\text { where } C(0)=C^{\prime}(0)=0, C^{\prime \prime} \geq 0 \text { and } C(1)<\bar{p}_{B} X-1
$$

We introduce the $\varepsilon$ cost of loan application so as to ensure that firms will prefer to apply sequentially for loans: only after its application for a loan is rejected, it applies at another bank. This avoids duplication of screening costs compared to the situation where all firms would apply simultaneously to all banks. The upper bound on the maximal screening cost is sufficiently low to ensure that a single bank will profit from making loans to firms which pass the screening test.

Convexity of the screening cost $C(\cdot)$ is a crucial assumption of this model, which differentiates it from Broecker's. We believe that it is a realistic depiction of reality: most banks rely upon a department of credit specialists to screen loan applications. As in other models of labour, it is reasonable to assume that their costs are convex in the quantity of loan applications that they process. In addition, the paper focusses on the realistic scenario where banks cannot costlessly discard a potentially large number of loan applicants. This assumption is again crucial to our analysis.

The loan application process works as follows. Assumptions (A3) and (A1) together imply that banks will not lend to category $A$ firms and so in the first stage banks simultaneously

\footnotetext{
${ }^{1}$ If banks were happy to lend without screening then a single bank would be willing to undercut its competitors and to screen if the benefits it derived from doing so outweighed the costs of screening. Hence, with an appropriate

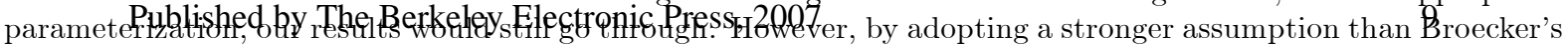
we are able to rule out equilibria of the type where one group of banks charges a higher interest rate than another group of banks. Our additional assumption does not play a role in showing existence of pure strategy equilibria.
} 
announce whether they wish to provide credit and if they do so, the rate $r \in[0, X]$ at which they will lend to type $B$ firms. Firms then make sequential applications for loans. ${ }^{2}$ We assume that a bank cannot distinguish or discriminate between a firm that directly applies to this bank and a firm that has applied (and was rejected) elsewhere.

Broecker shows (Proposition 2.1) that under assumptions (A1) - (A3) and with no costs of loan application or of screening, this one-stage game has no equilibrium in pure strategies. In the following section we demonstrate that for appropriate functions $C(\cdot)$, the additional assumption $\left(\mathrm{A} 4^{\prime}\right)$ guaranteeing sequential loan applications is sufficient to overturn this result. An important step in the proof consists of determining the number of applicants each bank has to screen and the average repay probability of approved loans. In particular, we need this in the case of $L$ banks setting the same interest rate and all other active banks setting strictly higher interest rates.

Lemma 1. Suppose that $L$ banks offer the lowest interest rate. Let $f(L)$ be the number of firms screened by any of these banks, and let $h_{k}(L)$ be the number of clients of type $k(k=a, b)$ which each of these banks has. Then

$$
\begin{aligned}
f(L) & =\frac{1}{L}\left\{l\left(\frac{1-q_{a}^{L}}{1-q_{a}}\right)+(1-l)\left(\frac{1-q_{b}^{L}}{1-q_{b}}\right)\right\} . \\
h_{a}(L) & =\frac{l\left(1-q_{a}^{L}\right)}{L} \\
h_{b}(L) & =\frac{(1-l)\left(1-q_{b}^{L}\right)}{L}
\end{aligned}
$$

Proof: In the appendix.

\section{Existence of a Pure Strategy Equilibria}

In this section we demonstrate the existence of a pure strategy equilibrium for the game which we defined in section 3 . We start by making the following definition:

DeFinition 1. In pure strategy combinations where $r$ is the lowest rate and it is charged by $x$ banks:

1. $U(r, x)$ is the expected profit earned by each of the $x$ banks;

2. $r_{0}(x)$ is the lowest value for $r$ at which the $x$ banks make non negative profits.

The number of banks $N$ is exogenously given: if $N$ is large enough, it will not be possible for every bank to earn positive profits if they all offer loans. ${ }^{3}$ We therefore assume that banks can
http://www.hepress.com/heite

\footnotetext{
${ }^{2}$ In Broecker's original paper firms make simultaneous loan applications: our modification of his game is rendered necessary by assumption $\left(\mathrm{A} 4^{\prime}\right)$.

${ }^{3}$ This is even true if we ignore the screening costs: see Broecker (1990).
} 
elect to be inactive in equilibrium, and that this earns them zero profits. ${ }^{4}$ With this assumption, a symmetric pure strategy Nash equilibrium in which $L$ active banks each charge an interest rate $r$ will be characterized by the following conditions:

(PS1) Banks must be prepared to lend at $r$, and firms must be prepared to borrow:

$$
X \geq r \geq r_{0}(L)
$$

This implies in particular that $U(r, L) \geq 0$, so that no active bank prefers to be inactive.

(PS2) No active bank should wish to lower its interest rate slightly:

$$
U(r, L) \geq U(r, 1)
$$

Once (PS1) is satisfied, a sufficient condition for (PS2) to hold is that $0 \geq U(r, 1)$, which can be restated as $r \leq r_{0}(1)$.

(PS3) No active bank should benefit from an upward deviation, even to the highest possible interest rate $X$.

Finally, if $L<N$, so that there are inactive banks, three additional conditions have to be imposed:

(PS4) None of the $N-L$ inactive banks should elect to become active at a lower interest rate;

(PS5) None of the $N-L$ inactive banks should elect to become active at the same interest rate;

(PS6) None of the $N-L$ inactive banks should elect to become active at a higher interest rate.

To demonstrate that conditions PS1-6 can be satisfied simultaneously, we require an assumption regarding the quality of firms which receive opposing results from screenings by two different banks. Inequality (ES) below states that banks are unwilling to lend to such firms, ${ }^{5}$ so that a bank will discard a positive result from its own screening if it knows that a competitor has already received a negative result for the same firm.

$$
\frac{l q_{a}\left(1-q_{a}\right) p_{a}+(1-l) q_{b}\left(1-q_{b}\right) p_{b}}{l q_{a}\left(1-q_{a}\right)+(1-l) q_{b}\left(1-q_{b}\right)} X<1 .
$$

With a symmetric screening technology such that $1>q_{a}=1-q_{b}>1 / 2$, obtaining two opposite results is equivalent to having no test result at all. In this case, the left hand side of

\footnotetext{
${ }^{4}$ Alternatively, we could weaken the equilibrium concept and modify (PS1) so as to allow banks to bear losses, which is in line with the idea that the number of banks is fixed in the short run and variable through entry/exit

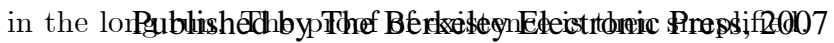

${ }^{5}$ This assumption was made by Broecker (1990) in the second part of his paper to show existence of a pure strategy equilibrium when banks can withdraw from the market after observing all interest rates offered.
} 
the inequality reduces to $\bar{p} X$ and the assumption (ES) is equivalent to assumption (A3). In general, inequality (ES) is satisfied when banks are relatively better at identifying type $b$ than type $a$ firms. It certainly holds in the limiting case where $1>q_{a}>q_{b}=0$ and type $b$ firms are perfectly identified since in this case $(\mathrm{ES})$ reduces to $p_{a} X<1$. On the other hand, it is not satisfied when $1=q_{a}>q_{b}>0$ so that the screening technology perfectly identifies type $a$ firms, since (ES) then reduces to $p_{b} X<1$. Note that (ES) holds independently of $L$, a point that will greatly simplify the analysis.

Under (ES), no bank has an incentive to charge a higher interest rate than its competitors:

Lemma 2. When (PS1) is satisfied, condition (ES) implies condition (PS3).

Proof: In the appendix.

The intuition for lemma 2 is as follows. Deviating to a higher interest rate will attract only those borrowers who have already been rejected by banks charging the lower interest rate. Under (ES) the deviating bank will discard its own signal in this case and assumption (A3), which states that unscreened projects have negative present value, then ensures that the applicant will be rejected.

We now examine sufficient conditions for condition (PS2) to be satisfied. It transpires that it is sufficient to assume that the minimum break-even interest rate $r_{0}$ is greater with one than with two banks. When there are two banks each will screen fewer firms. When $C(x) \equiv 0$ as in Broecker's paper this is not important and we demonstrate in the appendix that $r_{0}(L)$ is increasing in $L$. However, if $C(\cdot)$ is sufficiently convex then this result is reversed at $L=1$ :

Lemma 3. $r_{0}(1)>r_{0}(2)$ if and only if the following convexity condition $(C)$ is satisfied:

$$
\begin{aligned}
& \frac{l p_{a}\left(1-q_{a}\right)\left[\left(1+q_{a}\right) C(1)-2 C(f(2))\right]}{l p_{a}\left(1-q_{a}\right)+(1-l) p_{b}\left(1-q_{b}\right)}+\frac{(1-l) p_{b}\left(1-q_{b}\right)\left[\left(1+q_{b}\right) C(1)-2 C(f(2))\right]}{l p_{a}\left(1-q_{a}\right)+(1-l) p_{b}\left(1-q_{b}\right)} \\
& >l\left(1-q_{a}\right)\left(1-q_{b}\right)\left(q_{a}-q_{b}\right)(1-l)\left(p_{b}-p_{a}\right) /\left(l p_{a}\left(1-q_{a}\right)+(1-l) p_{b}\left(1-q_{b}\right)\right) .
\end{aligned}
$$

Proof: In the appendix.

Note that the right-hand side of $(\mathrm{C})$ is strictly positive and independent of $C(\cdot)$. The lefthand side of the inequality is a weighted average of $\left(1+q_{a}\right) C(1)-2 C(f(2))$ and $\left(1+q_{b}\right) C(1)-$ $2 C(f(2))$. If the weights used were $l$ and $(1-l)$ respectively, this average would be exactly equal to zero in case of linear cost function $C(\cdot)\left(\right.$ since $\left.2 f(2)=l\left(1+q_{a}\right)+(1-l)\left(1+q_{b}\right)\right)$, but http://www.bepress.com/bejte

in the case of a strictly convex cost function the average is strictly positive. 


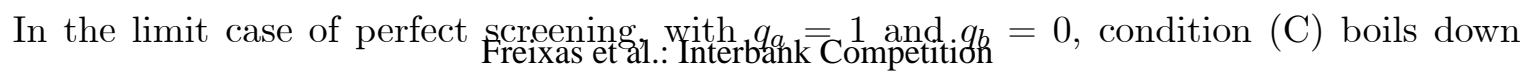
to $C(1)>2 C(f(2))$. Since $f(2)=\frac{1+l}{2}$, this reduces to $C(1)>2 C\left(\frac{1+l}{2}\right)$, stating again that linear costs would not satisfy the condition, and that a degree of convexity is required which is increasing in $l$.

Conditions (ES) and (C) are sufficient to guarantee the existence of a pure strategy equilibrium:

THEOREM 1. Assume that (ES) holds. When screening costs are sufficiently convex (in particular, when $(C)$ holds) a pure strategy Nash equilibrium exists in which more than one bank is active and where all active banks charge the same interest rate $r$. Moreover, in any pure strategy Nash equilibrium all active banks charge the same interest rate.

The formal proof of this result appears in the appendix. The convexity condition (C) is essential because, by lemma 3 , it guarantees that $r_{0}(L)$ cannot be minimized at $L=1$. Hence either $r_{0}(L)$ has an interior minimum turning point (not necessarily unique) $L^{*} \in \mathbb{N}(1, N)$, or $r_{0}$ is minimized at $N$. In the former case (PS2) is satisfied for $L=L^{*}$ and an asymmetric equilibrium obtains in which some banks elect to remain inactive, while in the latter it is satisfied at $L=N$ and a symmetric equilibrium obtains in which every bank is active. Note that the two types of equilibria are not mutually exclusive.

In both the asymmetric equilibrium case $\left(L=L^{*}\right)$ and the symmetric equilibrium case $(L=N)$, an equilibrium exists for any interest rate in a range above $r_{0}(L)$. As a result, active banks make equilibrium profits. Since the equilibrium interest rate can lie within a range, it is indeterminate. We do not see this as a negative result. The specific characteristics of the credit market when screening is accounted for leads quite naturally to this result. Any coordination device which allowed us fully to characterize the equilibrium (Central Bank announcement, colluding to the highest possible interest rate, ...) would therefore be ad hoc.

One interesting implication of interest rate indeterminacy is that it partially disconnects credit from the marginal cost of funds. Only in the case of large shocks will some adjustment be necessary. As interest rates hit the lower bound $r_{0}$, or the number of active banks has to adjust, we may switch from one equilibrium to another one. In general, small changes in the model's parameters will produce small changes in the rates $r_{0}$ so that the interest rate $r$ will remain in the same interval. Hence interest rates will not react immediately to changes in marginal costs, and in particular to changes in interbank rates. This is of interest, as it is consistent with the Published by The Berkeley Electronic Press, 2007 observation that interest rates for loans change only sporadically, as discussed in section 2.2 above, and which still lacks a fully satisfactory theoretical justification. 
Finally, recall that the number of active banks is somewhat indeterminate. However, we can establish that the number of active banks is bounded above, and hence that the symmetric equilibrium $(L=N)$ cannot occur for large enough $N$ :

Lemma 4. There exists a maximum number of active banks, $M$.

\section{Comparative Statics}

We define social welfare in this model to be the total present value of all financed projects, less the total screening costs:

$$
W(L) \equiv l\left(1-q_{a}^{L}\right)\left(p_{a} X-1\right)+(1-l)\left(1-q_{b}^{L}\right)\left(p_{b} X-1\right)-L C(f(L)) .
$$

In this section we examine the effect of $L$ upon social welfare and upon bank profitability for the following specific cost function:

$$
C(s)=\left\{\begin{array}{cc}
0, & s<1 \\
c, & \text { otherwise }
\end{array}\right.
$$

We interpret $C(\cdot)$ as describing the costs of a capacity-constrained bank. Recall that $C(s)$ is the cost of screening $s$ applicants. Hence, $s$ can be interpreted as market share. A single bank is just able to screen all applicants but at a high cost. We assume that $c>0$ is such that a single bank charging $X$ will make small but positive profits and that condition (C) is satisfied so that existence of pure strategy equilibria is guaranteed as before: undercutting is optimal only when high interest rates are charged.

Proposition 1. When screening costs are given by equation (2), welfare in equilibrium is a decreasing function of $L$.

Proof: In the appendix.

As we discuss in the introduction, the intuition behind proposition 1 is simple: a bad project has more chance of securing a loan when there are more banks. Hence, provided an increase in the number of banks does not reduce aggregate screening costs significantly, it will lower welfare. This remark suggests that proposition 1 can be generalized to more general cost functions. For example, it remains true when the cost function $C(s)$ is linear for $s<1$. Also, for all convex cost functions it will be the case that welfare is eventually decreasing in the number of active http://www.bepress.com/bejte

banks, that is, for $n>n^{*}$, for some $n^{*}$. The intuition behind this is that the reduction in total screening cost by having one extra bank becomes small when many banks are active. We 


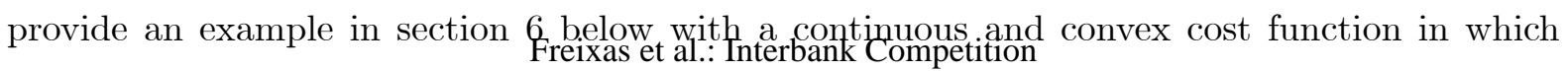
welfare is decreasing in the number of active banks in equilibrium.

\section{An Illustrative Example}

We now demonstrate that the pure strategy equilibrium conditions (PS1) - (PS6) are compatible by considering numerical specifications for the parameters of the model. We also consider welfare and profits for this example.

Let $q_{a}=0.75, q_{b}=0.6, p_{a}=0.3, p_{b}=0.7, l=0.4, X=1.84$, and $C(x)=0.02 x^{5}$. It is easy to check that assumptions (A1)-(A3) are satisfied. It is also easily verified that the screening costs are so low that a single bank charging $X$ would make positive profit. (Broecker, 1990, shows that this follows from (A2) in the case of no screening costs.) Straightforward calculations yield

$$
\begin{aligned}
& r_{0}(1)=1.818>r_{0}(2)=1.789>r_{0}(3)=1.785, \\
& r_{0}(4)=1.792<r_{0}(5)=1.801<r_{0}(6)=1.810<r_{0}(1)<r_{0}(n) \text { for } n \geq 7, \\
& r_{0}(n)>X \text { for all } n>11 .
\end{aligned}
$$

We assume that there are $N \geq 12$ potential banks in the market. There are no pure strategy equilibria with one or two active banks, since any inactive bank would make strictly positive profits by mimicking an active bank. Furthermore, no pure equilibria exist where more than six banks enter, since these banks can only break even by charging an interest rate strictly above $r_{0}(1)$, in which case an inactive bank could make a positive profit by undercutting slightly below $r_{0}(1)$. On the other hand, for $L=3,4$, and 5 , it is an equilibrium for $L$ active banks to charge any interest rate $r \in\left[r_{0}(L), r_{0}(L+1)\right]$. It is also an equilibrium for six banks to charge any interest rate $r \in\left[r_{0}(6), r_{0}(1)\right]$.

Observe that the more banks are active in equilibrium, the higher is the equilibrium interest rate. The reason for this is twofold: on the one hand, a few banks charging a relatively high interest rate would provoke entry by additional banks; on the other hand, when many banks offer the same interest rate, average credit quality is quite low and hence the interest rate must be quite high to ensure that the banks break even.

The interest rate simply determines a transfer between firms and banks and hence does not affect social welfare $W(L)$. Total surplus depends only upon the number of active banks in Published by The Berkeley Electronic Press, 2007 equilibrium. With more active banks, more and on average worse projects get financed. This effect is welfare decreasing, but is partially offset by the convexity of the screening cost function. 
It can be easily calculated that the total welfare with $3,4,5$, and 6 banks equals, $W(3)=0.032$, $W(4)=0.028, W(5)=0.023$, and $W(6)=0.017$, respectively. Hence, welfare is highest with the least number of banks.

We now consider bank profits. Obviously, these depend upon the equilibrium interest as well as the number of active banks. Since for $L \in\{3,4,5,6\}$ it is an equilibrium for $L$ banks to charge $r_{0}(L)$, there are always equilibria in which banks make zero profits. We focus upon the maximal equilibrium profits. Simple calculations yield maximal individual bank profits of about $8 \times 10^{-4}, 10 \times 10^{-4}, 9 \times 10^{-4}$, and $7 \times 10^{-4}$ in the respective cases with $3,4,5$, and 6 banks. The highest per-bank profit is obtained with 4 active banks. Joint profits are maximized with 5 active banks.

\section{Heterogeneous Monitoring Skills}

In this section, we consider an extension of our model in which some banks are endowed with a better monitoring technology than the others. Specifically, we assume that these superior banks have a monitoring technology $\hat{q}_{a}, \hat{q}_{b}$ which satisfies the following assumptions:

$$
\begin{aligned}
& \hat{q}_{a}>q_{a} ; \\
& \hat{q}_{b}<q_{b} .
\end{aligned}
$$

Superior banks will thus reject less good (type $b$ ) firms and reject more bad (type $a$ ) firms than inferior banks do. The adverse selection effect is thus stronger in the presence of superior competitors. On the other hand, the adverse selection effect is less strong for superior banks than it is for inferior banks. This is most easily seen in the extreme case that superior banks have perfect monitoring technologies.

The existence and characterization of pure strategy equilibria will obviously depend on the number of inferior and superior banks, on how much better the superior technology is, and on the exact screening cost. In this Section we will assume that screening costs are given by (2) so that both superior and inferior banks have capacity constraints. Let us assume that firms know the quality of monitoring of each bank. When all the banks charge the same interest rate, firms will apply to the bank where they have the highest probability of being granted a loan. Hence, all type $b$ firms will in first instance apply to the superior banks, while type $a$ firms will exhaust the supply of inferior banks before applying to a superior bank. Hence, the inferior http://www.bepress.com/bejte

banks suffer from a "cherry-picking externality" (Morrison and White, 2004). If condition (ES) holds, an active inferior bank will make losses whenever a superior bank charges the same or 
a lower interest rate. Hence, in a pure strategy equilibrium either no inferior bank is active or two or more inferior banks charge the same low interest rate while one or more superior banks charge a much higher interest rate.

We are able to show that equilibria of the first type will certainly exist, provided that at least two banks have the superior technology. ${ }^{6}$ Namely, applying the construction of Section 4 applied to a model in which all banks have the superior monitoring technology, one finds that a number of superior banks coordinating on the same interest rate below $r_{0}(1)$ will constitute a pure strategy Nash equilibrium in this adjusted model. Obviously, inferior banks can do no better than remain inactive.

THEOREM 2. Suppose that there are at least two banks with superior technology $\left(\hat{q}_{a}, \hat{q}_{b}\right)$ with $\hat{q}_{a}>q_{a}$ and $\hat{q}_{b}<q_{b}$. Suppose furthermore that inequality (ES) holds when $q_{a}$ and $q_{b}$ are replaced by $\hat{q}_{a}$ and $\hat{q}_{b}$, respectively. Then there exists a pure strategy equilibrium in which only superior banks are active, and all pure strategy equilibria are of this type.

Proof: The proof is similar to that of theorem 1.

This straightforward extension of theorem 1 is of interest for several reasons. First, the equilibrium we are envisaging is one where the number of active banks is limited by the access they have to the superior technology. Second, if the acquisition of the superior technology is the result of learning by doing, then it fully justifies Shaffer's (1998) idea of a winner's curse in the market for credit.

\section{Conclusion}

In this paper we explore credit market equilibrium when banks perform costly screening. When the screening technology is sufficiently accurate and sufficiently convex, we are able to prove that pure strategy equilibria exist. This complements Broecker's (1990) result that there is no pure strategy equilibrium when screening is costless. Moreover, equilibrium prices in our model are the result of a coordination process. This implies the existence of positive equilibrium profits as well as a disconnect between marginal cost and prices.

Apart from the convexity assumption, a crucial implicit assumption we make is that banks cannot refuse applicants without screening. Given the convexity of screening costs banks have incentives to ration applicants. They could potentially do this by falsely claiming that applicants Published by The Berkeley Electronic Press, 2007

\footnotetext{
${ }^{6}$ The second type of equilibrium, in which inferior banks charge low interest rates and superior banks charge high interest rates, may exist in very special cases. However, we were not able to find parameters consistent with the model and satisfying this condition.
} 
failed the test and therefore refuse credit. Our implicitiossumption basically says that banks can only refuse credit if they have some proof to back up their decision. A full analysis of the case where banks can ration applicants is beyond the scope of this paper and is left to future research. We also made quite some specific assumptions with regards to the parameters of the model, some of which are stronger than those made by Broecker (1990). These stronger assumptions were only made to focus on a particular type of pure strategy equilibria, namely those where all active banks charge the same interest rate. They do not facilitate the existence of pure strategy equilibria. For example, if the tests of different banks are imperfectly and positively correlated, the adverse selection effect would be reduced since clients rejected by competing banks would be more likely to be rejected by one own's test. This would create the possibility of pure strategy equilibria where one group of banks coordinates on a low interest rate and attracts good risk firms while a second group of banks charges a higher interest rate and attracts, on average, high risk firms.

Finally, a substantial literature has argued that welfare is enhanced by allowing banks to extract rents from their lending relationships. The prior literature has typically argued that this rent is required to satisfy a screening incentive compatibility constraint. We approach this problem from an alternative perspective. Proposition 1 shows that an increase in the number of banks may decrease welfare. The reason in our model is that a higher number of banks raises the probability that a bad creditor will obtain a loan after visiting all of them. Our work therefore provides a new argument to support the policy recommendation that entry to the credit market should be restricted.

\section{Appendix}

We start by establishing and proving some supporting results.

\section{Proof of Lemma 1}

Proof: The number of type $a$ firms that are screened precisely $k$ times $(k<L)$ is $l\left(1-q_{a}\right) q_{a}^{k-1}$ (as they are assigned to category $A$ the first $k-1$ times, and then to category $B$ ). The number of type $a$ firms that are screened exactly $L$ times is $l q_{a}^{L-1}$ (they are assigned the first $L-1$ times to category $A$ ). So the expected number of screenings for type $a$ firms equals

$$
\begin{array}{r}
\mathrm{http} / / / \mathrm{www} \cdot \text { bepress.com/bejte } \\
\qquad\left(1-q_{a}\right) \sum_{k=1}^{L-1} k q_{a}^{k-1}+l L q_{a}^{L-1}=l \frac{1-q_{a}^{L}}{1-q_{a}}
\end{array}
$$


Similarly for type $b$ firms the expected number of screenings, equals

$$
(1-l)\left(1-q_{b}\right) \sum_{k=1}^{L-1} k q_{b}^{k-1}+(1-l) L q_{b}^{L-1}=(1-l) \frac{1-q_{b}^{L}}{1-q_{b}}
$$

Given the symmetry between banks, the expected number of screenings equals $f(L)$.

Of all the applicants screened by a particular bank, only those who are assigned to category $B$ receive a loan. This means that each bank has $l\left(1-q_{a}^{L}\right) / L$ clients of type $a$, and $(1-l)\left(1-q_{b}^{L}\right) / L$ clients of type $b$.

Using the notation of this lemma we can establish the following expression for the expected profit $U(r, x)$, defined in part one of definition 1 :

$$
\begin{aligned}
U(r, L) & =h_{a}(L)\left(p_{a} r-1\right)+h_{b}(L)\left(p_{b} r-1\right)-C(f(L)) \\
& =\frac{l\left(1-q_{a}^{L}\right)}{L}\left(p_{a} r-1\right)+\frac{(1-l)\left(1-q_{b}^{L}\right)}{L}\left(p_{b} r-1\right)-C(f(L)) .
\end{aligned}
$$

The function $r_{0}(L)$ defined in part 2 of definition 1 is the solution to $U\left(r_{0}, L\right)=0$ :

$$
r_{0}(L)=\frac{l\left(1-q_{a}^{L}\right)+(1-l)\left(1-q_{b}^{L}\right)+L C(f(L))}{l p_{a}\left(1-q_{a}^{L}\right)+p_{b}(1-l)\left(1-q_{b}^{L}\right)} .
$$

We make the following definition:

Definition 2. In an equilibrium with $L$ active banks, let $V(\rho, L)$ be the profit which a bank earns if it deviates to an interest rate $\rho$, while its $L-1$ competitors charge an interest rate $r<\rho$.

The deviating bank in this definition will screen the $l q_{a}^{L-1}+(1-l) q_{b}^{L-1}$ firms which are not awarded loans at the other banks. On average, it will give loans to $l q_{a}^{L-1}\left(1-q_{a}\right)$ firms of type $a$, and $(1-l) q_{b}^{L-1}\left(1-q_{b}\right)$ firms of type $b$. Its profits will therefore be given by the following expression:

$$
V(\rho, L)=l q_{a}^{L-1}\left(1-q_{a}\right)\left(p_{a} \rho-1\right)+(1-l) q_{b}^{L-1}\left(1-q_{b}\right)\left(p_{b} \rho-1\right)-C\left(l q_{a}^{L-1}+(1-l) q_{b}^{L-1}\right) .
$$

When $L-1$ banks charge interest rate $r$, let $\rho_{0}(L)$ be the lowest interest rate in excess of $r$ at which another bank could extend loans and break even. $\rho_{0}(L)$ is the solution to $V\left(\rho_{0}, L\right)=0$ :

$$
\rho_{0}(L)=\frac{l q_{a}^{L-1}\left(1-q_{a}\right)+(1-l) q_{b}^{L-1}\left(1-q_{b}\right)+C\left(l q_{a}^{L-1}+(1-l) q_{b}^{L-1}\right)}{l q_{a}^{L-1}\left(1-q_{a}\right) p_{a}+(1-l) q_{b}^{L-1}\left(1-q_{b}\right) p_{b}} .
$$


It is sufficient to show that $\rho_{0}(L)>X$ for all $L \geq 0$. Clearly,

$$
\rho_{0}(L) \geq \frac{l q_{a}^{L}\left(1-q_{a}\right)+(1-l) q_{b}^{L}\left(1-q_{b}\right)}{l q_{a}^{L}\left(1-q_{a}\right) p_{a}+(1-l) q_{b}^{L}\left(1-q_{b}\right) p_{b}} \geq \frac{l q_{a}\left(1-q_{a}\right)+(1-l) q_{b}\left(1-q_{b}\right)}{l q_{a}\left(1-q_{a}\right) p_{a}+(1-l) q_{b}\left(1-q_{b}\right) p_{b}}>X
$$

The first inequality follows from $C(\cdot) \geq 0$, the second inequality holds since

$$
\begin{aligned}
& \frac{d}{d L}\left\{\frac{l q_{a}^{L}\left(1-q_{a}\right)+(1-l) q_{b}^{L}\left(1-q_{b}\right)}{l q_{a}^{L}\left(1-q_{a}\right) p_{a}+(1-l) q_{b}^{L}\left(1-q_{b}\right) p_{b}}\right\}= \\
& \frac{l q_{a}^{L} q_{b}^{L}\left(\ln q_{a}-\ln q_{b}\right)(1-l)\left(1-q_{a}\right)\left(1-q_{b}\right)\left(p_{b}-p_{a}\right)}{\left(l q_{a}^{L}\left(1-q_{a}\right) p_{a}+(1-l) q_{b}^{L}\left(1-q_{b}\right) p_{b}\right)^{2}}>0 .
\end{aligned}
$$

so that $\frac{l q_{a}^{L}\left(1-q_{a}\right)+(1-l) q_{b}^{L}\left(1-q_{b}\right)}{l q_{a}^{L}\left(1-q_{a}\right) p_{a}+(1-l) q_{b}^{L}\left(1-q_{b}\right) p_{b}}$ is an increasing function of $L$, and the third follows directly from (ES).

\section{Proof of Lemma 3}

The result follows from straightforward manipulations, using the expression for $r_{0}(L)$.

\section{Proof of Theorem 1}

From lemma 2, condition (PS3) is satisfied provided $U(r, L) \geq 0$. On the other hand, we know from the final condition in $(\mathrm{A} 5 \prime)$ that $r_{0}(1)<X$ and that $r_{0}(1)>r_{0}(2)$ (because of $(\mathrm{C})$ ).

Two cases are to be considered. Either (i) $r_{0}(1) \geq r_{0}(2) \geq \ldots \geq r_{0}(N)$ or (ii) there exists $L^{*}<N$ such that $r_{0}\left(L^{*}\right)<\min \left\{r_{0}(1), r_{0}\left(L^{*}+1\right)\right\}$.

We consider first case (i): it is clear that it is an equilibrium for all $N$ banks to charge $r_{0}(1)$ as (PS1) and (PS2) then hold, so does (PS3) and there is no inactive bank ( $L=N)$, so (PS4), (PS5) and (PS6) are trivially satisfied. Note that since $U(r, L)$ is linear in $r$, for any $L>1$ with $r_{0}(L)<r_{0}(1)$ there exists a unique real number $\eta_{L}$ such that $U\left(\eta_{L}, L\right)=U\left(\eta_{L}, 1\right)$. The previous arguments apply to show that for any $r \in\left[r_{0}(N), \min \left\{X, \eta_{N}\right\}\right]$, all $N$ banks charging $r$ is an equilibrium.

Consider now case (ii). Let $r \in\left(r_{0}\left(L^{*}\right), \min \left\{r_{0}(1), r_{0}\left(L^{*}+1\right)\right\}\right)$. It is obvious that the situation in which $L^{*}$ banks charge $r$ constitutes a pure strategy equilibrium: by the choice of $r$ conditions (PS1), (PS4), and (PS5) are satisfied. As observed before, this implies that also (PS2) is satisfied, and since $r_{0}^{\prime}(L)>X$ for all $L$ by lemma 2, this implies that $V\left(X, L^{*}+1\right)<0$

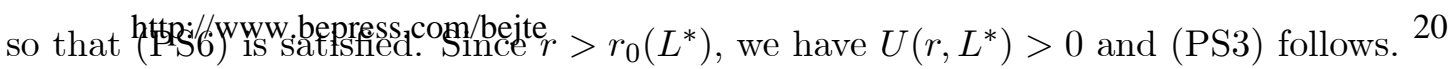

If in a pure strategy equilibrium two active banks charge different interest rates, the one 
who charges the higher interest rate makes negative profits because of lemma 2. Hence, active banks must necessarily charge the same interest rates.

\section{Proof of Lemma 4}

The proof procedes in three stages as follows:

Stage 1. Under $\left(A 5^{\prime}\right), \lim _{L \rightarrow \infty} L C(f(L))=0$, and thus $\lim _{L \rightarrow \infty} r_{0}(L)=1 /\left\{l p_{a}+(1-l) p_{b}\right\}=$ $1 / \bar{p}$

Proof: Set $\gamma=\left[\frac{l}{1-q_{a}}+\frac{1-l}{1-q_{b}}\right]$

$$
\begin{aligned}
\lim _{L \rightarrow \infty} L C(f(L)) & =\lim _{x \rightarrow 0} \frac{1}{x} C\left(f\left(\frac{1}{x}\right)\right) \\
& =\lim _{x \rightarrow 0} \frac{C\left(x\left[l\left(\frac{1-q_{a}^{1 / x}}{1-q_{a}}\right)+(1-l)\left(\frac{1-q_{b}^{1 / x}}{1-q_{b}}\right)\right]\right)}{x} \\
& \leq \lim _{x \rightarrow 0} \frac{C(x \gamma)}{x} \\
& =\lim _{x \rightarrow 0} \frac{\gamma C^{\prime}(x \gamma)}{1}=0
\end{aligned}
$$

Since under $\left(\mathrm{A} 5^{\prime}\right), C^{\prime}(0)=0$ and $L C(f(L)) \geq 0$ for all $L$, the result follows.

StAGe 2. Under (A3) and $\left(A 5^{\prime}\right)$ there exists $M$ such that $r_{0}(M) \leq r_{0}(1)$ and $r_{0}(L)>r_{0}(1)$ for all $L>M$.

Proof: By assumption (A3), $1 / \bar{p}>X$. Since $r_{0}(1)<X$ and $\lim _{L \rightarrow \infty} r_{0}(L)>X$, there exists $M$ such that $r_{0}(M) \leq r_{0}(1)$ and $r_{0}(L)>r_{0}(1)$ for all $L>M$.

Stage 3. When $U(r, L)>U(r, 1)$ there cannot be an equilibrium with $L$ banks. Hence $M$ is the maximum number of banks.

Proof: Now observe that $\frac{\partial}{\partial r} U(r, L)<\frac{\partial}{\partial r} U(r, 1)$. It follows that when $r_{0}(L)>r_{0}(1)$, we have $U(r, L)<U(r, 1)$ for any $r \geq r_{0}(L)$.

\section{Proof of Proposition 1}

There is no equilibrium in which just one bank enters. Suppose that there exists an equilibrium in which $L>1$ banks are active, and each charges $r_{L}^{*}$, and that there also exists an equilibrium

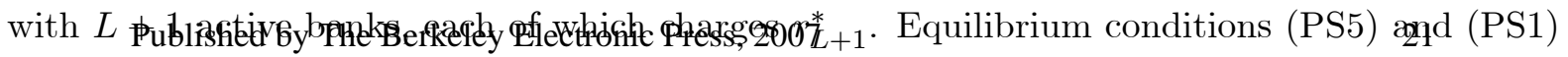
imply that $r_{L}^{*} \leq r_{0}(L+1) \leq r_{L+1}^{*} \leq X$. The difference in total welfare between the two 
equilibria is

$$
\begin{aligned}
& W(L+1)-W(L) \\
& =l\left(p_{a} X-1\right)\left(q_{a}^{L}-q_{a}^{L+1}\right)+(1-l)\left(p_{b} X-1\right)\left(q_{b}^{L}-q_{b}^{L+1}\right)-(L+1) C(f(L+1))+L C(f(L)) \\
& =V(X, L)+\left[C\left(l q_{a}^{L}+(1-l) q_{b}^{L}\right)+L C(f(L))-(L+1) C(f(L+1))\right] .
\end{aligned}
$$

When screening costs are given by equation $(2)$ and $L>1$, the square bracketed term disappears. Hence

$$
W(L+1)-W(L)=V(X, L) \leq 0,
$$

where the inequality follows from (PS6) in case $r_{L}^{*}<X$ : no inactive bank will enter and charge $X$ when $L$ banks charge $r_{L}^{*}<X$. In the case where $r_{L}^{*}=X$, then $r_{0}(L+1)=r_{L+1}^{*}=X$, which implies that $W(L+1)=0$, as banks would make zero profit and firms would enjoy no surplus in the equilibrium with $L+1$ active banks. Obviously, also in this case we have that $W(L+1)-W(L) \leq 0$.

\section{References}

Ausubel, L. M. (1991), 'The Failure of Competition in the Credit Card Market', American Economic Review, Vol. 81, No. 1 (March), pp. 50 - 81.

Broecker, T. (1990), 'Credit-Worthiness Tests and Interbank Competition', Econometrica, Vol. 58, No. 2 (March), pp. $429-452$.

Calem, P. S. and L. J. Mester (1995), 'Consumer Behavior and the Stickiness of Credit-Card Interest Rates', American Economic Review, Vol. 85, No. 5 (December), pp. 1327 - 36.

Chiappori, P.-A., D. Perez-Castrillo and T. Verdier (1995), 'Spatial Competition in the Banking System: Localization, Cross Subsides and the Regulation of Deposit Rates', European Economic Review, Vol. 39, No. 5 (May), pp. 889 - 918.

Dastidar, K. G. (1995), 'On the Existence of Pure Strategy Bertrand Equilibrium', Economic Theory, Vol. 5, No. 1 (February), pp. 19-32.

Dell'Ariccia, G., E. Friedman and R. Marquez (1999), 'Adverse Selection as a Barrier to Entry in the Banking Industry', RAND Journal of Economics, Vol. 30, No. 3 (Autumn), pp. 515 -534 .

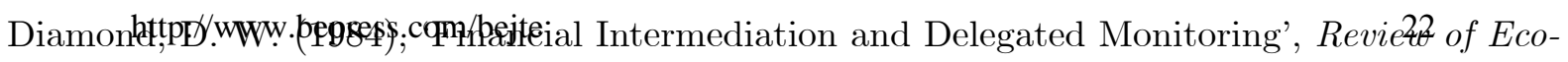
nomic Studies, Vol. 51, No. 3 (July), pp. 393-414. 
Emons, W. (2001), 'Imperfect Tests and Natural Insurance Monopolies', Journal of Industrial Economics, Vol. 49, No. 3 (September), pp. $247-268$.

Gale, D. and M. Hellwig (1985), 'Incentive-Compatible Debt Contracts: The One Period Problem', Review of Economic Studies, Vol. 52, No. 4 (October), pp. 647-663.

Hannan, T. H. and A. N. Berger (1991), 'The Rigidity of Prices: Evidence from the Banking Industry', American Economic Review, Vol. 81, No. 4 (September), pp. 938 - 945.

Holmstrom, B. and J. Tirole (1993), 'Market Liquidity and Performance Monitoring', Journal of Political Economy, Vol. 101, No. 4, pp. 678-709.

Marquez, R. (2002), 'Competition, Adverse Selection, and Information Dispersion in the Banking Industry', Review of Financial Studies, Vol. 15, No. 3 (Summer), pp. 901 - 926.

Matutes, C. and X. Vives (2000), 'Imperfect Competition, Risk Taking, and Competition in Banking', European Economic Review, Vol. 44, No. 1 (January), pp. 1-34.

Mester, L. J. (1994), 'Why Are Credit Card Rates Sticky?', Economic Theory, Vol. 4, No. 4 (May), pp. $505-530$.

Morrison, A. D. and L. White (2004), 'Level Playing Fields in International Financial Regulation', Working Paper 2004-FE-10, Oxford Financial Research Centre, University of Oxford, UK.

Petersen, M. A. and R. G. Rajan (1995), 'The Effect of Credit Market Competition on Lending Relationships', Quarterly Journal of Economics, Vol. 110 (May), pp. 407 - 443.

Rajan, R. G. (1992), 'Insiders and Outsiders: The Choice Between Informed and Arm's Length Debt', Journal of Finance, Vol. 47, No. 4 (September), pp. 1367-1400.

Riordan, M. H. (1993), 'Competition and Bank Performance: A Theoretical Perspective', in C. Mayer and X. Vives, eds, Capital Markets and Financial Intermediation, Cambridge University Press, Cambridge, UK, pp. $328-343$.

Shaffer, S. (1998), 'The Winner's Curse in Banking', Journal of Financial Intermediation, Vol. 7, No. 4 (October), pp. 359 - 392.

Sharpe, S. (1990), 'Asymmetric information, bank lending and implicit contracts: a stylized model of customer relationships', Journal of Finance, Vol. 45, pp. 1069-87.

Stiglitz, J. E. and A. Weiss (1981), 'Credit Rationing in Markets with Imperfect Information', The American Economic Review, Vol. 71, No. 3 (June), pp. 393-410.

Published by The Berkeley Electronic Press, 2007

Suarez, J. (1998), 'Risk-Taking and the Prudential Regulation of Banks', Investigaciones Economicas, Vol. 22, No. 3 (September), pp. 307 - 336. 
von Thadden, E.-L. (2004) 'Asymmetric Information Bank Lending, and Implicit Contracts: The Winner's Curse', Finance Research Letters, Vol. 1, No. 1 (March), pp. 11 - 23. 